\title{
Rotina e necessidades de apoio: relato de familiares de crianças de zero a dois anos, público alvo da Educação Especial
}

\author{
Michelle Roberta Pavão* \\ Danielli Silva Gualda ** \\ Fabiana Cia*** \\ Luciana Stoppa dos Santos**** \\ Ana Carolina Camargo Christovam*****
}

\section{Resumo}

Considerando que os primeiros anos de vida das crianças Público Alvo da Educação Especial (PAEE) despertam em seus familiares diferentes experiências e cuidados, o objetivo desta pesquisa foi identificar a rotina e as necessidades de apoio das famílias de crianças de zero a dois anos PAEE e relacionar tais variáveis. A amostra foi composta por 23 mães e um pai de criança PAEE. Para atender aos objetivos, os participantes responderam por meio de entrevista o "Inventário de Recursos do Ambiente Familiar - RAF" e o "Questionário sobre as necessidades das famílias - QNF". Foram realizadas análises descritivas e teste de correlação de Pearson. Os resultados mostraram que as crianças recebiam estímulos em casa, porém os pais apresentavam necessidades de informação, apoio e necessidades financeiras. Isto mostra o quanto esses fatores são importantes ao possibilitar às famílias a compreensão e aceitação da deficiência das crianças, além de auxiliar na organização familiar e solução de conflitos. Também é possível que pela idade das crianças, os pais ainda estejam em fase de adaptação e busca de informaçôes e serviços que possam auxiliar no desenvolvimento dos seus filhos. Portanto, sugerem-se estudos com amostras ampliadas e com populaçôes de diferentes idades para a generalização dos dados que possam embasar intervenções com famílias futuramente.

Palavras-chave: Crianças do público alvo da Educação Especial; Famílias;

Necessidades e recursos.

\footnotetext{
* Mestranda em Educação Especial pela Universidade Federal de São Carlos, São Carlos, São Paulo, Brasil.

** Doutoranda em Educação Especial pela Universidade Federal de São Carlos, São Carlos, São Paulo, Brasil.

*** Professora adjunta do Departamento de Psicologia e do Programa de Pós-Graduação pela Universidade Federal de São Carlos, São Carlos, São Paulo, Brasil.

**** Mestre em Educação Especial pela Universidade Federal de São Carlos, São Carlos, São Paulo, Brasil.

***** Doutora em Educação Especial pela Universidade Federal de São Carlos, São Carlos, São Paulo, Brasil.
} 


\section{Daily routine and suspport necessities: a story of relatives of children targeted by special education from zero to two years old}

\section{Abstratc}

Considering that the Children targeted by special education's first years of life unveil, in their parents, several new experiences and care needs, the aim of this research was to identify the daily routine and the needs of families that have special education children from zero to two years old and relate these variables. The sample was composed by 23 mothers and a father of a child targeted by special education. To fill the objectives, the participants answered, by an interview,the "Inventory of the family environment resources (FER)" and the "Questionnaire about the needs of families (QNF)". Descritive analysis and the Pearson's correlation test were done. The results shown that the children received estimulation at home, but the parents shown lack of information and support, and financial problems. That shows the importance of these factors, because they make possible for the family to comprehend and accept the child's deficiency, in addition to help in the family's organization and problem solving. It is also possibe that considering the children's age, their parents are still in a adaptation phase, or looking for information and services that can help in their children's development. Therefore, studies with larger samples with different ages are suggested for the generalization of the data that can base future interventions with the families.

Keywords: Children targeted by special education; Families; Needs and resources.

\section{Introdução}

Situando-se a família na sociedade contemporânea atual pode-se notar que seus modelos e definiçôes se configuram como uma construção histórica, política e social (PANIAGUA; PALACIOS, 2007; PINHEIRO; BIASOLI-ALVES, 2008). Nesse sentido, tal instituição é considerada como uma estrutura central no desenvolvimento de seus membros, garantindo a sobrevivência física, a transmissão da cultura, do significado social e dos conhecimentos comuns acumulados ao longo das geraçôes (DESSEN; BRAZ, 2005; CIA, 2009), ou seja, se responsabiliza pela educação primária dos sujeitos.

De fato, nas diferentes fases do desenvolvimento da criança, a família passa por transformaçôes, no que diz respeito aos cuidados, envolvimentos e práticas. No caso dos indivíduos Público Alvo da Educação Especial (PAEE ${ }^{1}$ ), essas transformaçôes podem ser mais frequentes e intensas devido a maior exigência da participação dos pais, com as novas informaçôes, os programas de estimulação precoce e diversos outros atendimentos baseados nas especificidades de cada deficiência (BRUNHARA; PETEAN, 1999; BUSCAGLIA, 2006; MARTINS, PIRES, 2008). 
Assim, evidencia-se que as alteraçóes ocorridas no equilíbrio familiar com a chegada de uma criança PAEE podem ser tanto negativas quanto positivas, pois há inúmeros fatores que afetam as experiências e atitudes de seus membros, por exemplo, a deficiência do filho, os recursos financeiros da família, o suporte social, as informaçóes/orientaçóes recebidas desde a descoberta e, alguns outros aspectos relacionados às características pessoais dos mesmos (TURNBULL et al., 2006).

Dessa forma, ao considerar a complexidade que envolve o sistema familiar, bem como a importância da mesma para o desenvolvimento biológico, social, afetivo e educacional de seus sujeitos, torna-se necessário averiguar algumas variáveis inseridas nesse contexto a fim de compreender melhor seu funcionamento e, também, as possíveis necessidades que seus membros possam ter em relação aos seus filhos PAEE.

\section{Necessidades e recursos: implicações nas famílias de crianças PAEE}

Oferecer recursos, organizar rotina e atender as necessidades das famílias de crianças PAEE são aspectos de extrema importância para a aceitação de suas especificidades, na superação de sentimentos ambivalentes e ainda, no desencadeamento de experiências que ajudaráo no desenvolvimento e cuidado com seus filhos.

Santos (2014) investigou o impacto de diferentes variáveis familiares no ciclo de desenvolvimento de crianças do PAEE. Participaram da pesquisa 45 pais de crianças PAEE na faixa etária de zero e dez anos de idade, que freqüentavam serviços de estimulação precoce, atendimento educacional especializado ou escolas comuns. Para a coleta de dados foram utilizados os seguintes instrumentos: roteiro de entrevista semiestruturada, questionário de recursos e estresses, questionário sobre as necessidades das famílias, Inventário EC-HOME, escala de emponderamento familiar, Inventário de recursos do ambiente familiar e questionário de suporte social. Os dados obtidos mostraram que, em relação aos recursos, os pais tinham intensa participaçáo na rotina dos filhos tanto em cuidados diários, quanto em atendimentos especializados dos mesmos. Considerando as necessidades, os pais apontaram, mais uma vez, a necessidade de informação sobre o desenvolvimento dos seus filhos e, ainda, necessidades operacionais e financeiras.

Com o objetivo de identificar e diferenciar as necessidades e as prioridades das famílias de crianças autistas apoiadas pela intervenção precoce, Raimundo (2015) entrevistou 123 pais que tinham filhos autistas entre três e seis anos de idade. Os resultados mostraram que as famílias necessitavam mais de informaçóes sobre o desenvolvimento das crianças, os recursos e os apoios existentes na comunidade que pudessem atender as suas demandas. Considerando estes aspectos, a autora destacou a importância de intervençóes centradas na família para que seja possível auxiliá-las em relação ao desenvolvimento dos filhos e que ajudassem na aceitação e compreensão da deficiência dos mesmos, sendo necessário propiciar recursos nos contextos educacionais e assistenciais.

Sabe-se que o fato dos pais terem uma boa rotina e participarem intensamente na vida de seus filhos, se mostra essencial para o bom funcionamento da vida familiar, pois o estudo de Batista e França (2007) aponta que quando a rotina dentro de tal

Revista Educação Especial | v. 31 | n. 61 | p. 447-462 | abr./jun. 2018

Santa Maria 
contexto é estabelecida, propicia-se a individualidade e a busca da auto-realização de seus membros, assegurando experiências que serão significativas para o desenvolvimento das crianças.

Seguindo tal linha de raciocínio, outros estudos (DUNST, 2000; D'AVILA-BACARJI; MARTURANO; ELIAS, 2005; GUALDA; BORGES; CIA, 2013; SPINAZOLA, 2014) também indicaram que os recursos e os suportes/apoios práticos, instrumentais, informacionais e sociais, de forma independente ou combinada, influenciavam o funcionamento familiar nos cuidados prestados à criança PAEE e, consequentemente, contribuíam para o melhor comportamento de seus membros em relação às necessidades que surgiam.

Pode-se afirmar que se as famílias estabelecerem reciprocidade e constância nas interações com seus membros, pessoas e serviços da comunidade, a interação no dia a dia irá influenciar no desenvolvimento e aprendizagem de todos. Além disso, tais necessidades dependerão das características desses familiares, assim como da criança PAEE em um determinado tempo.

Todos os fatores citados podem se relacionar com o fundamento desta pesquisa, pois estudar as necessidades e a rotina requer analisar, de forma complexa, o ambiente e os estímulos que as crianças recebem em casa. Ainda assim, notou-se que algumas pesquisas desenvolvidas no contexto nacional (GUALDA, 2012; GUALDA, et al., 2013; SPINAZOLA, 2013; SANTOS, 2014;) investigaram as variáveis familiares de crianças PAEE, mas não obtiveram como controle da variável a idade de zero a dois anos, etapa esta considerada crítica por se tratar das experiências e cuidados iniciais a partir do diagnóstico informado aos pais.

Por esses motivos, os objetivos do presente estudo foram: (a) identificar a rotina e as necessidades de apoio das famílias de crianças de zero a dois anos do PAEE; e (b) relacionar as necessidades e a rotina das famílias de crianças de zero a dois anos do PAEE.

\section{Método}

\section{Amostra}

A amostra do estudo foi composta por 24 familiares, dentre os quais 23 eram mães e um pai de crianças PAEE. Foram considerados os seguintes critérios: (a) ser pai, mãe ou responsável de uma criança PAEE; (b) a criança ter entre zero e dois anos de idade; (c) a criança possuir um diagnóstico que a englobe no PAEE; e/ou (d) receber serviços da educação especial em centros especializados.

A média de idade dos participantes foi de 29 anos e, em relação ao nível de escolaridade evidenciou que a maioria possuía Ensino Fundamental completo $(n=6)$, seguido pelo Ensino Superior completo $(n=6)$, Ensino Fundamental incompleto $(n=5)$, Ensino Médio completo $(n=4)$, Ensino Médio incompleto $(n=3)$. 
Considerando as crianças PAEE das famílias investigadas, 14 eram do sexo masculino e 10 do feminino, com média de um ano de idade. Os diagnósticos encontrados entre elas foram de hidrocefalia, artrogripose, má formação no cerebelo, atraso no desenvolvimento (avaliado previamente pelos locais que eram atendidas), síndrome de Down e fissura lábio palatal.

\section{Local de coleta dos dados}

A coleta de dados ocorreu em instituiçóes de ensino especial, escolas comuns e instituiçôes especializadas. Destaca-se que foram coletados dados em três cidades do interior do estado de Sáo Paulo.

\section{Instrumentos}

Foram utilizados dois instrumentos com questóes fechadas, sendo um Inventário de Recursos do Ambiente Familiar - RAF (MARTURANO, 1999), e um Questionário sobre as Necessidades das Famílias - QNF (PEREIRA, 1996). Em relação ao RAF as questôes focaram as atividades diárias com horários definidos (momentos da criança e momentos em família). O QNF apresentou 28 itens distribuídos em seis tópicos: necessidades de informação, necessidades de apoio, explicar aos outros, serviços da comunidade, necessidades financeiras e funcionamento da vida familiar.

\section{Procedimentos de coleta de dados}

Após o projeto de pesquisa ser aprovado pelo Comitê de Ética (CAEE: 10010112.9.0000.5504) foram selecionadas as famílias de crianças PAEE que se encaixavam nos critérios de inclusão de participantes do presente estudo. A princípio, as pesquisadoras obtiveram uma carta de aceite dos dirigentes das instituiçóes que ofereciam os serviços especializados, bem como informaçôes dos familiares de crianças PAEE. Assim, com os que consentiram a participação, foi assinado o Termo de Consentimento Livre e Esclarecido e agendado o dia e o horário para realização da entrevista.

\section{Procedimento de análise dos dados}

Por meio das questóes do RAF e do QNF foram obtidos dados quantitativos, em que foram analisados usando métodos descritivos. Para relacionar as variáveis entre o nível de necessidades familiares e a rotina estabelecida no ambiente familiar, foi utilizado o teste de correlação de Pearson (COZBY, 2006; SAMPIERI; et al., 2006).

\section{Resultados e discussões}

\section{Relato dos pais: rotina e as possíveis necessidades das famílias}

A Tabela 1 mostra se as famílias costumavam se reunir com os filhos PAEE e, também, se as crianças apresentavam rotina para realizar atividades diárias. 
Tabela 1 - Rotina e reunióes familiares estabelecidas com as crianças PAEE em casa ${ }^{2}$

\begin{tabular}{|l|l|l|}
\hline $\begin{array}{l}\text { Inventário de recursos do Ambiente familiar - } \\
\text { RAF }\end{array}$ & & Média \\
\hline Se o filho tem hora certa para: & & \\
\hline Jantar & 1,87 & 0,34 \\
\hline Fazer lição & 1,80 & 0,45 \\
\hline Almoçar & 1,74 & 0,54 \\
\hline Tomar banho & 1,70 & 0,56 \\
\hline Levantar-se de manhã & 1,57 & 0,66 \\
\hline Ir dormir & 1,52 & 0,60 \\
\hline Brincar & 1,22 & 0,56 \\
\hline Assistir TV & 1,00 & 0,81 \\
\hline Total da subescala & 1,7 & 0,49 \\
\hline Sua família costuma se reunir & & \\
\hline No jantar & 1,78 & 0,42 \\
\hline Nos finais de semana & 1,68 & 0,57 \\
\hline À noite para assistir TV & 1,52 & 0,59 \\
\hline Em casa & 1,48 & 0,59 \\
\hline No almoço & 1,35 & 0,71 \\
\hline No café da manhá & 0,91 & 0,67 \\
\hline Total da subescala & 1,45 & 0,35 \\
\hline
\end{tabular}

Levando em consideração o relato dos pais, os dados da Tabela 1 mostraram que, na maioria dos casos, as crianças mais possuíam horários estabelecidos para jantar, fazer a lição de casa, almoçar e tomar banho. No entanto, salienta-se que nessa faixa etária ainda não há tarefas para serem realizadas em casa. Assim, tal dado pode ser interpretado como momentos em que os pais estimulavam seus filhos em casa com atividades pedagógicas.

Em relação aos itens brincar e assistir TV notou-se que as crianças PAEE investigadas nem sempre possuíam horários definidos para realizá-los. Segundo Gualda (2012) é importante estabelecer uma rotina em todas as atividades direcionadas para a criança, pois por meio dela a mesma percebe que todas suas açóes têm hora certa para ocorrer.

Com base nas reuniōes familiares estabelecidas pelos participantes, observouse que as mesmas ocorriam com maior frequência na hora do jantar e nos finais de semana ao passo que, com menor intensidade evidenciou-se os horários de almoço e de café da manhã. Acredita-se que o motivo das reunióes ocorrerem dessa forma nas famílias investigadas, se dava pelo fato de seus membros estarem trabalhando fora de 
casa, ou ainda, devido aos compromissos diários relacionados à criança PAEE, como os diversos serviços de estimulaçáo realizados nos centros especializados. A Tabela 2 apresenta as necessidades de informação das famílias.

Tabela 2 - Necessidades de informação das famílias ${ }^{3}$

\begin{tabular}{|l|l|l|}
\hline $\begin{array}{l}\text { Questionário sobre as Necessidades das } \\
\text { Famílias - QNF }\end{array}$ & \multicolumn{1}{|c|}{ Média } & D.P. \\
\hline Fator 1 - Necessidades de informação & & 0,70 \\
\hline $\begin{array}{l}\text { Necessito de maior informaçáo sobre os serviços } \\
\text { e os apoios de que meu filho poderá beneficiar } \\
\text { no futuro }\end{array}$ & 2,7 & 0,78 \\
\hline $\begin{array}{l}\text { Necessito de maior informação sobre os serviços e } \\
\text { os apoios que presentemente estão indicados para } \\
\text { meu filho }\end{array}$ & 2,61 & 0,78 \\
\hline $\begin{array}{l}\text { Necessito de maior informaçáo sobre a maneira } \\
\text { como a criança cresce e se desenvolve }\end{array}$ & 2,61 & 0,72 \\
\hline $\begin{array}{l}\text { Necessito de maior informação sobre a maneira } \\
\text { de ensinar o meu filho }\end{array}$ & 2,52 & 0,82 \\
\hline $\begin{array}{l}\text { Necessito de maior informação sobre a deficiência } \\
\text { e as necessidades específicas do meu fillho }\end{array}$ & 2,17 & 0,88 \\
\hline $\begin{array}{l}\text { Necessito de maior informação sobre a maneira } \\
\text { de lidar com meu filho }\end{array}$ & 1,96 & 1,00 \\
\hline $\begin{array}{l}\text { Necessito de maior informação sobre a maneira } \\
\text { de falar com meu filho }\end{array}$ & 1,78 & 0,54 \\
\hline Total da subescala & 2,34 & \\
\hline
\end{tabular}

Segundo os dados da Tabela 2, foi possível notar que as famílias possuíam maiores necessidades em relação aos serviços e apoios que os filhos poderiam se beneficiar no futuro, os serviços e apoios que eram mais indicados no momento atual que estavam vivendo, e informaçôes sobre como o filho cresce e se desenvolve.

Percebe-se que as necessidades mais evidenciadas nesse fator são compatíveis com a faixa etária investigada. $\mathrm{O}$ fato de essas famílias terem recebido o diagnóstico há pouco tempo, ou ainda das que estão sendo avaliadas pelos centros especializados, acabavam gerando tais incertezas e dúvidas.

Com base nessas questôes, Fiamenghi e Messa (2007) salientam que quanto mais acesso à informaçáo os pais tiverem, menos sentimentos de insegurança e medo surgirão. Por consequência, a partir disso, as famílias conseguem buscar programas que as auxiliem de forma segura e concreta, além de encontrar facilmente melhores soluções quando houver algum problema relacionado aos filhos PAEE. Por outro 
lado, Spinazola (2014) ressalta que a ausência de informaçóes pode aumentar o nível de estresse dos pais, dificultando o processo de estimulação e a busca precoce por recursos que possam ajudar os filhos.

De tal modo, as informaçōes podem ainda direcionar as práticas parentais ao nível micro e masossistêmico, ao passo que ajudam a estabelecer melhores interaçôes e relaçôes no funcionamento familiar, bem como na interpretação das políticas públicas com diretrizes que são mais indicadas nos serviços e recursos disponíveis para seus filhos.

A Tabela 3 apresenta as necessidades de apoio das famílias.

Tabela 3 - Necessidades de apoio das famílias ${ }^{4}$

\begin{tabular}{|l|l|l|}
\hline $\begin{array}{l}\text { Questionário sobre as Necessidades das } \\
\text { Famílias - QNF }\end{array}$ & Média & D.P. \\
\hline Fator 2 - Necessidades de apoio & & 0,94 \\
\hline $\begin{array}{l}\text { Necessito de mais oportunidade para me } \\
\text { encontrar e falar com os pais de outras crianças } \\
\text { deficientes }\end{array}$ & 2,39 & 0,95 \\
\hline $\begin{array}{l}\text { Necessito de mais tempo para falar com os } \\
\text { professores e terapeutas do meu filho }\end{array}$ & 2,22 & 0,98 \\
\hline $\begin{array}{l}\text { Gostaria de me encontrar regularmente com um } \\
\text { conselheiro (médico, psicólogo, assistente social) } \\
\text { com quem possa falar sobre os problemas que a } \\
\text { deficiência do meu filho coloca }\end{array}$ & 2,04 & 0,98 \\
\hline Necessito de mais tempo para mim próprio. & 2,00 & 0,98 \\
\hline $\begin{array}{l}\text { Necessito de informaçóes escritas sobre os pais } \\
\text { das crianças que têm os mesmos problemas com } \\
\text { meu filho }\end{array}$ & 2,00 & 0,98 \\
\hline Necessito de ter mais amigos com quem conversar & 1,83 & 0,94 \\
\hline $\begin{array}{l}\text { Necessito de ter alguém da minha família com } \\
\text { quem eu possa falar mais sobre os problemas que } \\
\text { a deficiência do meu filho coloca }\end{array}$ & 1,73 & 0,66 \\
\hline Total da subescala & 2,05 & \\
\hline
\end{tabular}

Considerando o Fator 2 - necessidade de apoio, os dados da Tabela 3 destacaram que os familiares possuíam maiores necessidades de terem oportunidades para falar com outros pais de crianças PAEE e, também, de terem mais tempo para falar com os professores e terapeutas de seus filhos. Tais dados sugerem que, os demais membros familiares, de imediato, talvez não contribuíssem tanto com os questionamentos que surgiam em relaçáo às especificidades dos filhos, enquanto as experiências de outros pais e profissionais poderiam ser mais positivas e favoráveis nesse momento. 
Tais questóes mostram que o suporte social colabora para que as famílias se reestruturem diante de barreiras sociais, psicológicas e financeiras (BARBOSA; et al., 2009). Conforme os pais se deparam com outras pessoas que passam pela mesma situação que eles, os sentimentos de medo e insegurança vão se transformando em compreensão e aceitação da deficiência dos filhos, pois a troca de informaçóes pode auxiliar no entendimento e na busca de serviços de apoio que ajudarão as crianças (ROCHA; et al, 2015).

A Tabela 4 irá apresentas as necessidades de explicar a outros das famílias.

Tabela 4 - Necessidades de explicar aos outros das famílias ${ }^{5}$

\begin{tabular}{|l|l|l|}
\hline $\begin{array}{l}\text { Questionário sobre as Necessidades das } \\
\text { Famílias - QNF }\end{array}$ & \multicolumn{1}{|c|}{ Média } & D.P. \\
\hline Fator 3 - Explicar a outros & & 0,97 \\
\hline $\begin{array}{l}\text { Necessito de mais ajuda sobre a forma de explicar } \\
\text { a situação do meu filho aos amigos }\end{array}$ & 1,7 & 0,94 \\
\hline $\begin{array}{l}\text { Necessito de ajuda para explicar a situação do } \\
\text { meu filho a outras crianças }\end{array}$ & 1,65 & 0,85 \\
\hline $\begin{array}{l}\text { Necessito de ajuda para saber como responder, } \\
\text { quando amigos, vizinhos ou estranhos, me façam } \\
\text { perguntas sobre a situaçáo do meu filho }\end{array}$ & 1,52 & 0,85 \\
\hline $\begin{array}{l}\text { Meu marido (ou minha mulher) precisa de ajuda } \\
\text { para compreender e aceitar melhor a situaçâo do } \\
\text { nosso filho }\end{array}$ & 1,52 & 0,59 \\
\hline Total da subescala & 1,60 & \\
\hline
\end{tabular}

A Tabela 4 mostra que no total da subescala do Fator 3 (explicar aos outros), os familiares demonstraram não terem tanta certeza se possuíam esse tipo de ajuda. Esses dados nos levam a refletir que tais participantes poderiam estar se sentindo mais esclarecidos quanto aos filhos, sendo este um aspecto positivo, já que as crianças desse estudo possuíam média de um ano de idade, ou seja, ainda era recente a descoberta do diagnóstico.

Os dados dessa tabela possuem ligação direta com os da Tabela 2, pois a falta de informaçáo e entendimento sobre a deficiência do filho pode acarretar na não necessidade de explicar aos outros, ou de não precisarem de ajuda para tal (SANTOS, 2014).

A Tabela 5 apresenta as necessidades das famílias em relação aos serviços da comunidade. 
Tabela 5 - Necessidades das famílias relacionadas aos serviços da comunidade ${ }^{6}$

\begin{tabular}{|l|l|l|}
\hline $\begin{array}{l}\text { Questionário sobre as Necessidades das } \\
\text { Famílias - QNF }\end{array}$ & Média & D.P. \\
\hline Fator 4 - Serviços da comunidade & & 1,01 \\
\hline $\begin{array}{l}\text { Necessito de ajuda para encontrar um serviço } \\
\text { que quando eu tiver necessidade (descansar, ir ao } \\
\text { cinema, a uma festa, etc.) fique com meu filho, } \\
\text { por períodos curtos, e que esteja habilitado para } \\
\text { assumir essa responsabilidade }\end{array}$ & 2,13 & 0,97 \\
\hline $\begin{array}{l}\text { Necessito de ajuda para encontrar um serviço de } \\
\text { apoio social e educativo para o meu filho }\end{array}$ & 1,87 & 0,78 \\
\hline $\begin{array}{l}\text { Necessito de ajuda para encontrar um médico que } \\
\text { me compreenda e compreenda as necessidades do } \\
\text { meu filho }\end{array}$ & 1,39 & 0,52 \\
\hline Total da subescala & 1,8 & \\
\hline
\end{tabular}

A partir dos dados da Tabela 5, notou-se que os familiares tinham maior necessidade para encontrar um serviço para quando fossem descansar, ir ao cinema ou a uma festa, pudessem deixar o filho com uma pessoa habilitada à assumir a responsabilidade de ficar com o mesmo.

É natural que os pais necessitem de mais momentos de lazer, pois o fato de possuírem vários compromissos relacionados ao filho PAEE, tornam essas ocasiōes menos comuns até por conta das demandas que os filhos exigem e da dificuldade de encontrar outros serviços ou pessoas que possam ficar com as crianças durante estes períodos (SPINAZOLA, 2014). Outra razáo que pode promover a falta de momentos de lazer se dá por meio da superproteçáo dos pais e o medo de deixar a responsabilidade dos cuidados de seus filhos com outras pessoas (FIAMENGHI; MESSA; 2007). Dando continuidade as necessidades encontradas por meio do QNF, a Tabela 6 apresenta os resultados em relação ao Fator 5.

Tabela 6 - Necessidades das famílias de crianças entre zero e dois anos PAEE, em relação ao Fator $5^{7}$

\begin{tabular}{|l|l|l|}
\hline Questionário sobre as Necessidades das Famílias - QNF & Média & \multicolumn{1}{|c|}{ D.P. } \\
\hline Fator 5 - Necessidades financeiras & & 1,00 \\
\hline $\begin{array}{l}\text { Necessito de maior ajuda no pagamento de despesas como: } \\
\text { alimentaçáo, cuidados médicos, transportes, ajudas técnicas } \\
\text { (cadeira de rodas, prótese auditiva, máquina Braille, etc.) }\end{array}$ & 2,09 & 0,96 \\
\hline $\begin{array}{l}\text { Necessito de maior ajuda para obter o material ou } \\
\text { equipamento especial de que meu filho necessita }\end{array}$ & 1,74 & \\
\hline
\end{tabular}




\begin{tabular}{|l|l|l|}
\hline $\begin{array}{l}\text { Necessito de maior ajuda para pagar despesas } \\
\text { com: terapeutas, estabelecimento de educação } \\
\text { especial ou outros serviços de que o meu filho } \\
\text { necessita }\end{array}$ & 1,7 & 0,96 \\
\hline $\begin{array}{l}\text { Necessito de maior ajuda para pagar a serviços de } \\
\text { colocação temporária }\end{array}$ & 1,52 & 0,90 \\
\hline Total da subescala & 1,76 & 0,6 \\
\hline
\end{tabular}

No total da subescala foi possível observar que a maioria das famílias não tinha tanta certeza se possuíam necessidades financeiras relacionadas ao filho PAEE. Tal dado pode estar relacionado ao fato dessas crianças terem recebido o diagnóstico precoce, pois por meio dele as mesmas passam a ter direitos legais em relação aos serviços públicos destinados aos sujeitos PAEE (BRASIL, 2008). Mesmo tais famílias não apresentando um elevado nível socioeconômico, o equilíbrio familiar acaba sendo mantido nesse caso, quando seus membros possuem serviços públicos direcionados aos seus filhos. A Tabela 7 apresenta as necessidades da vida familiar

Tabela 7 - Necessidades da vida familiar ${ }^{8}$

\begin{tabular}{|l|l|l|}
\hline $\begin{array}{l}\text { Questionário sobre as Necessidades das } \\
\text { Famílias - QNF }\end{array}$ & \multicolumn{1}{|c|}{ Média } & D.P. \\
\hline Fator 6 - Funcionamento da vida familiar & & \\
\hline $\begin{array}{l}\text { A nossa família necessita de ajuda para encontrar } \\
\text { forma de, nos momentos difíceis, nos apoiarmos } \\
\text { mutuamente }\end{array}$ & 1,65 & 0,94 \\
\hline $\begin{array}{l}\text { A nossa família necessita de ajuda para discutir } \\
\text { problemas e encontrar soluçóes }\end{array}$ & 1,52 & 0,90 \\
\hline $\begin{array}{l}\text { A nossa família necessita de ajuda para decidir } \\
\text { quem fará as tarefas domésticas, quem tomará } \\
\text { conta das crianças e outras tarefas familiares }\end{array}$ & 1,52 & 0,90 \\
\hline Total da subescala & 1,57 & 0,79 \\
\hline
\end{tabular}

A partir dos dados da Tabela 7 , notou-se que os participantes não possuíam tanta certeza se necessitavam de ajuda no funcionamento da vida familiar. Com isso, pode-se refletir que a deficiência do filho não acarretou o mau funcionamento familiar, ou seja, possivelmente seus membros conseguiram se adaptar favoravelmente as tarefas do dia a dia, os cuidados com o filho e a resolução de problemas.

Regen (2005) salienta que um ambiente saudável, propiciador do desenvolvimento das crianças é aquele que oferece apoio quando necessário para que a mesma passe a ter referências seguras e consistentes, sendo capazes de estabelecerem autoestima, relaçôes de trocas e acreditar em si. 


\section{Relação das necessidades familiares com a rotina das famílias de crianças PAEE de zero a dois anos}

A Tabela 8 apresenta as relaçóes estabelecidas entre o nível de necessidades e a rotina oferecida às crianças PAEE de zero a dois anos no ambiente familiar.

Tabela 8. Relação entre o nível de necessidades e a rotina oferecida às crianças entre zero a dois anos PAEE no ambiente familiar ${ }^{9}$

\begin{tabular}{|c|c|c|c|c|c|c|c|c|}
\hline Variáveis & \begin{tabular}{|l|}
$(\mathrm{QNF})$ \\
1
\end{tabular} & $\begin{array}{l}(\mathrm{QNF}) \\
2\end{array}$ & $\begin{array}{l}\text { (QNF) } \\
3\end{array}$ & $\begin{array}{l}\text { (QNF) } \\
4 \\
\end{array}$ & $\begin{array}{l}\text { (QNF) } \\
5\end{array}$ & $\begin{array}{l}(\mathrm{QNF}) \\
6\end{array}$ & $\begin{array}{l}\text { Q N F } \\
\text { total }\end{array}$ & $\begin{array}{l}\text { (RAF) } \\
7 \\
\end{array}$ \\
\hline (QNF) 1 & - & $569^{* * *}$ & - & - & - & 651 & $888^{* *}$ & - \\
\hline (QNF) 2 & & - & 512 & $522^{*}$ & - & 651 & - & - \\
\hline (QNF) 3 & & & - & $449^{*}$ & - & 639 & $700^{* *}$ & $977^{* *}$ \\
\hline (QNF) 4 & & & & - & 432 & - & $619^{* *}$ & - \\
\hline (QNF) 5 & & & & & - & - & $576^{* *}$ & - \\
\hline (QNF) 6 & & & & & & - & $751^{* *}$ & $-1,000^{* *}$ \\
\hline
\end{tabular}

A partir dos dados da Tabela 8, observou-se que quanto maior eram as necessidades de informação, maiores eram as necessidades de apoio, além das necessidades totais. Para isso, é fundamental que os programas de apoio e intervenção sejam centrados nas famílias e no papel que cada membro desse contexto exerce sobre o desenvolvimento das crianças, estimulando-os e encorajando-os para trazer melhorias na qualidade de vida dos filhos, além de tornarem-se aptos para solucionar seus próprios problemas (WILLIAMS; AIELLO, 2001). Azevedo (2014) complementa ainda que, quanto maior o nível de emponderamento, menores devem ser os níveis de necessidades e estresse entre as famílias de crianças PAEE.

Verificou-se ainda, que quanto maior eram as necessidades de apoio, mais as famílias precisavam de informação, de explicar a outros sobre a deficiência dos filhos PAEE, de serviços da comunidade e um maior funcionamento da vida familiar. Essas variáveis também se correlacionaram com as necessidades totais. Quando a família tem acesso aos procedimentos que podem ajudar no desenvolvimento dos seus filhos, sentem-se mais seguras, conseguem atender melhor as demandas dos mesmos e relacionar-se com outras pessoas (CIA, 2009).

Em relação ao Fator 3, quanto maior eram as necessidades de explicar aos outros, maiores eram as necessidades de apoio, de serviços da comunidade, funcionamento da vida familiar e as necessidades totais. Por outro lado, considerando a rotina, quanto maior eram as necessidades de explicar aos outros, menor eram as chances de a criança ter hora certa para cumprir atividades de rotina diária.

Ainda neste pressuposto, a necessidade de explicar a deficiência dos filhos às outras pessoas estava relacionada com a necessidade de ter mais apoio, de utilizar-se de serviços da comunidade e da forma como a família se organizava no seu cotidiano. 
Os pais que são mais esclarecidos quanto a isso, não possuem todas essas necessidades, porque já devem estar mais adaptados aos serviços de apoio e da comunidade, quanto da rotina e organização da vida familiar (PANIÁGUA; PALÁCIOS, 2007).

Quanto maior eram as necessidades de serviços da comunidade, maiores eram as necessidades de apoio, de explicar a outros e financeiras, correlacionando-se com as necessidades totais. Fiamenghi e Messa (2007) demonstram que a participação em programas de intervençấo e programas de auxílio pode ser de muita ajuda para pais de crianças PAEE, pois gera a oportunidade de compartilhar vivências com outras pessoas que passam pela mesma realidade e, assim, auxiliar no incremento de informaçóes e dos recursos de enfrentamento e adaptação.

Além disso, quanto maiores eram as necessidades financeiras, maiores eram as necessidades totais, ou seja, a condição financeira influenciou, de maneira geral, nas necessidades que essas famílias tinham. Matsukura, Marturano e Oishi (2002) salientam que melhores condiçóes financeiras podem influenciar no processo de desenvolvimento e aperfeiçoamento das redes de apoio.

Foi possível perceber também que quanto maior eram as necessidades diante do funcionamento da vida familiar, maiores eram as necessidades de apoio, de explicar aos outros e às necessidades totais. Isso significa que famílias com bom funcionamento da vida familiar buscam mais apoios e sentem a necessidade de serviços que sejam apropriados para a criança, talvez porque sejam mais exigentes em relação aos serviços que são oferecidos aos seus filhos. Aspecto que contribui ainda, para a ajuda nas necessidades de explicar aos outros e as necessidades totais, pois a própria família acaba agindo como rede de apoio e seus membros acabam desempenhando bons papéis no desenvolvimento das crianças (DESSEN; BRAZ, 2005).

Em relação ao fator da rotina do ambiente familiar, quanto mais o filho tinha hora certa para realizar as atividades de vida diária, menos era preciso explicar aos outros, bem como o funcionamento da vida familiar. Provavelmente, as famílias já estão mais esclarecidas em relação às necessidades dos filhos, mais adaptadas às demandas que são exigidas aos cuidados dos mesmos e mais seguras de si para explicar aos outros sobre as deficiências Também é possível que essas famílias fossem mais organizadas, dividissem os papéis dentro de casa, não tivessem tantas dificuldades para discutir os problemas e encontrar soluçóes rápidas.

Portanto, acredita-se que pela idade das crianças, os pais ainda estão em fase de adaptação e busca de informaçôes e serviços que possam auxiliar o desenvolvimento dos seus filhos. Além do que, os pais receberam a notícia da deficiência há pouco tempo, podendo justificar tais necessidades e as maneiras de organização das rotinas em relação às variáveis de correlação.

\section{Considerações finais}

Por meio do RAF foi possível observar que as crianças recebiam estímulos em casa, mas ainda é necessário trabalhar com os pais a importância de disponibilizar para os filhos uma diversidade de materiais e de realizar várias atividades com os mes- 
mos. Quanto as maiores dificuldades encontradas dentro do ambiente familiar eram: (a) necessidades de informação e (b) necessidades de apoio. Isso mostra o quanto esses fatores são importantes para a compreensão e aceitação da deficiência, além da solução de conflitos e organização familiar, pois quanto mais essas necessidades são supridas, mais os pais conseguem estabelecer rotinas e participarem da vida dos filhos.

Com os resultados obtidos, sugerem-se estudos com amostras ampliadas e com populaçóes de diferentes idades para a generalizaçáo dos dados e comparaçáo entre as necessidades e rotinas nas diversas fases do desenvolvimento humano. Com o levantamento desses dados é possível desenvolver futuros programas interventivos focados nas famílias de crianças PAEE.

\section{Referências}

AZEVEDO, T.L. Programa de intervençáo precoce com pais: impactos no bem-estar familiar e na estimulação infantil. Relatório disponibilizado pela autora, 2014.

BARBOSA, M.A.M.; PETTENGILL, M.A.M.; FARIAS T.L.; LEMES, LC. Cuidado da criança com deficiência: suporte social acessado pelas mães. v. 3. n. 3, Revista Gaúcha. p. 406-412, 2009.

BATISTA, S.; FRANÇA, R. Família de pessoas com deficiência: Desafios e superação. Revista de divulgação técnico-científica do ICPG, v.3 n. 10, p. 117-121, 2007.

BRASIL. Ministério da Educaçấo. Lei No 12.796, de 4 de Abril de 2013. Brasília, DF, 2013.

BRASIL. Decreto No 7.611, de 17 de novembro de 2011. Diário Oficial [da] República Federativa do Brasil, Poder Executivo, Brasília, DF, 18 nov. 2011. Seção 1, n. 221, p. 12.

BRASIL. Ministério da Educação. Política Nacional de Educaçáo Especial na Perspectiva da Educaçáo Inclusiva. Brasília, DF, 2008. 15 p.

BUSCAGLIA, L. O Papel da Família. In: BUSCAGLIA, L. (Org.). Os deficientes e seus Pais - um desafio ao aconselhamento. Rio de Janeiro: Record, 2006. p. 77-90.

BRONFENBRENNER, U. Bioecologia do desenvolvimento humano: Tornando os seres humanos mais humanos. São Paulo: Artmed, 2011. 310 p.

BRONFRENBRENNER, U.; MORRIS, P. The ecology of developmental processes. In: LERNER, R.M; DAMON, W (org.). Handbook of child psychology. New York: John Wiley \& sons, V. 1. P. 993-1027. 1998.

BRUNHARA, F.; PETEAN, E. B. L. Mães e filhos especiais: reaçôes, sentimentos e explicaçôes à deficiência da criança. v. 9, n. 16. Ribeirão Preto: Cadernos de Psicologia e Educação, Paidéia, p. 31-40, 1999.

CIA, F. Um programa para aprimorar o envolvimento paterno: Impactos no desenvolvimento do filho. 2009. f. 347. Tese de Doutorado, Programa de Pós-Graduação em Educação Especial, Universidade Federal de São Carlos, São Carlos, São Paulo, 2009.

CIA, F.; PAMPLIN, R.C.O.; WILLIAMS, L.C.A. O impacto do envolvimento parental no desempenho acadêmico de crianças escolares. v. 13, n. 2. Psicologia em Estudo, p. 251-260, 2008.

COZBY, P. C. Métodos de pesquisa em ciências do comportamento. $2^{\text {a }}$ ed., São Paulo: Editora Atlas, 2006, p. 454.

D'AVILA-BACARJI, K.M.G; MARTURANO, E.M.; ELIAS, L.C.S. Suporte parental: um estudo sobre crianças com queixas escolares. v. 10, n. 1. Maringá: Psicologia em Estudo. p. 107-115, 2005.

DESSEN, M.A.; BRAZ, M.P. A família e suas inter-relaçóes com o desenvolvimento humano. In: DESSEN, M.A.; COSTA JUNIOR, A.L. (Orgs.). A ciência do desenvolvimento humano - tendências atuais e perspectivas futuras. São Paulo: Artmed, p. 113-131, 2005.

DUNST, C. J. Revisting "Rethinking early intervention". Topics in Early Childhood Special Education, v. 20, n. 2, p. 95-104, 2000.

FIAMENGHI, A.G; MESSA, A. Pais, filhos e deficiência: Estudos das relaçôes familiares. Psicologia: Ciência e profissão, v. 27, n. 2, p. 236-245, 2007. 
GUALDA, D. S. Relaçáo família-escola e identificaçáo das necessidades e dos recursos dos pais de pré -escolares incluídos. $94 \mathrm{f}$. Trabalho de conclusão de curso. Licenciatura em educação especial, Universidade Federal de São Carlos, 2012.

GUALDA, D. S.; BORGES, L.; CIA, F. Famílias de crianças com necessidades educacionais especiais: recursos e necessidades de apoio. v. 26. Revista Educação Especial. p. 307-330, 2013

MARQUES, M. H.; Dixe, M.A.R. Crianças e jovens autistas: impacto na dinâmica familiar e pessoal de seus pais. Archives of Clinical Psychiatry, São Paulo, v. 38, n. 2. p. 66-70. 2011.

MARTINS, L.A.R.; PIRES M.J. Políticas e práticas educacionais inclusivas. ed. 1. Natal: Edufrn, 2008. p. 322.

MARTURANO, E.M. Recursos no ambiente familiar e dificuldades de aprendizagem na escola. v.15, n. 2 . Psicologia: Teoria e Pesquisa, 1999. p. 135-142.

MATSUKURA, T.S.; MARTURANO, E.M.; OISHI, J. O questionário de suporte social (SSQ): estudos de adaptação para o português. v. 10, n. 5. Revista Latino-Americana de Enfermagem. 2002. p. 685-681.

NARVAZ, M.G.; KOLLER, S.H. O modelo bioecológico do desenvolvimento humano. In: KOLLER, S.H. (Org.). Ecologia do desenvolvimento humano - Pesquisa e Intervenção no Brasil. São Paulo: Casa do Psicólogo, 2004. p. 51-65.

PANIAGUA, G. As famílias de crianças com necessidades educativas especiais. v. 3. Porto Alegre: Artmed, 2004. p. 330-346.

PANIAGUA, G; PALACIOS, J. Alternativas metodológicas para o dia a dia .In: In: COLL, C.; MARCHESI, A.; PALACIOS, J. (Orgs.). Educação Infantil - resposta educativa à diversidade. Porto Alegre: Artmed, 2007. p. 171-197

PEREIRA, F. As representaçóes dos professores de Educaçáo Especial e as necessidades das famílias. 132 f. Tese de Doutorado em Educação - Secretariado Nacional para Reabilitaçáo e Integração das Pessoas com Deficiência, Portugal, 1996.

PINHEIRO, M. H. C.; BIASOLI-ALVES, Z. .M.M. A família como base. In: WEBER, L.; DESSEN, M. A. N. D. (Org.). Família e desenvolvimento: visōes interdisciplinares. Curitiba: Juruá Editora, 2008, p. 21-34.

RAIMUNDO, A. I. V. J. Intervençáo Precoce e Perturbaçáo do Espetro do Autismo: necessidades e Prioridades das Famílias de Crianças dos 3-6 anos de idade. 2015. 181 f. Dissertaçáo (mestrado em educaçáo especial). Faculdade de motricidade humana. Universidade de Lisboa. 2015.

REGEN, M. A instituiçáo família e sua relaçáo com a deficiência. Revista Centro de Educaçáo. n. 27,2005, p. 1-8.

ROCHA, M.C.P.; CARVALHO, M.S.M.; FOSSA, M.A.; PEDROSO, G.E.R.; ROSSATO, L.M. Necessidades e dificuldades de famílias que vivenciam a experiência de ter uma criança com hidrocefalia. Saúde Revista. Piracicaba, v. 15, n. 40, p. 49-66. 2015.

SAMPIERI, R.H.; COLLADO, C.H.; LUCIO, P.B. Metodologia de pesquisa. ed. 3. São Paulo: McGraw -Hill, 2006. p. 583.

SANTOS, L.S. Comparaçáo de características familiares de crianças público alvo da educaçáo especial com diferentes faixas etárias. 2014. 189 f. Dissertação (mestrado em educação especial). Universidade Federal de São Carlos. São Carlos. 2014.

SPINAZOLA, C.C. Bem estar e qualidade da estimulação: comparando famílias de crianças público-alvo da educaçáo especial de zero a três anos e de quatro a seis anos. $93 \mathrm{f}$. Trabalho de conclusão de curso. Licenciatura em educação especial, Universidade Federal de São Carlos, 2014.

TURNBULL, A.; TURNBULL, R.; ERWIN, E.; SOODAK, L. Families, professionals, and exceptionality. New Jersey: Merrill Prentice Hall. 432 p. 2006.

WILLIAMS, L.C.A; AIELLO, A.L.R. O inventário Portage operacionalizado: intervenção com família. Publicado em 2001, reimpressão 2009. Sáo Paulo: Memnon, p. 299, 2001.

\section{Notas}

${ }^{1}$ O termo Público Alvo da Educaçáo Especial, representado pela sigla PAEE, tem sido utilizado atualmente nas pesquisas e aparece no presente artigo devido ao Decreto no 7.611/2011, que dispôe sobre a Educaçấo Especial e o Atendimento Educacional Especializado. Esse grupo compóe os sujeitos com deficiência, transtornos globais do desen- 
volvimento e altas habilidades ou superdotaçấo. Assim sendo, optamos por manter em todo o texto essa terminologia. ${ }^{2}$ A avaliação da escala variou entre ‘ 2,0 pontos' para sempre, ' 1,0 ponto' para às vezes ou 'zero ponto' para nunca.

${ }^{3}$ A avaliação das necessidades variou entre 1 (não necessito deste tipo de ajuda); 2 (não tenho certeza se necessito deste tipo de ajuda) e 3 (necessito deste tipo de ajuda).

${ }^{4} \mathrm{~A}$ avaliação das necessidades variou entre 1 (não necessito deste tipo de ajuda); 2 (não tenho certeza se necessito deste tipo de ajuda) e 3 (necessito deste tipo de ajuda).

${ }^{5}$ A avaliação das necessidades variou entre 1 (nẫo necessito deste tipo de ajuda); 2 (nấo tenho certeza se necessito deste tipo de ajuda) e 3 (necessito deste tipo de ajuda).

${ }^{6}$ A avaliação das necessidades variou entre 1 (não necessito deste tipo de ajuda); 2 (não tenho certeza se necessito deste tipo de ajuda) e 3 (necessito deste tipo de ajuda).

${ }^{7} \mathrm{~A}$ avaliação das necessidades variou entre 1 (não necessito deste tipo de ajuda); 2 (não tenho certeza se necessito deste tipo de ajuda) e 3 (necessito deste tipo de ajuda).

${ }^{8}$ A avaliação das necessidades variou entre 1 (não necessito deste tipo de ajuda); 2 (não tenho certeza se necessito deste tipo de ajuda) e 3 (necessito deste tipo de ajuda).

${ }^{9}+\mathrm{p}<0,1 ;{ }^{*} \mathrm{p}<0,05 ;{ }^{* *} \mathrm{p}<0,01$.Índices: (1) Necessidades de informação; (2) Necessidades de apoio; (3) Explicar aos outros; (4) Serviços da comunidade; (5) Necessidades financeiras; (6) Funcionamento da vida familiar e (7) rotina e reunióes familiares.

\section{Correspondência}

Michelle Roberta Paváo - Universidade Federal de São Carlos. Rodovia Washington Luís, s/n. CEP: 13565905. São Carlos, São Paulo, Brasil.

E-mail: pavaomichelle@hotmail.com-dany_gualda@yahoo.com.br-fabianacia@hotmail.com- lu_stoppa@ yahoo.com.br-carolchristovam@hotmail.com

Correspondência em 20 de março de 2017

Final em 20 de março de 2018 